\title{
LA SORDOCEGUERA, SU TRATAMIENTO NORMATIVO Y ATENCIÓN A LAS PERSONAS QUE LA PRESENTAN
}

\section{Deafblindness, its regulatory treatment and care}

\author{
Mónica Ruiz GonZÁLeZ \\ Universidad de Valladolid. Facultad de Educación y Trabajo Social. Paseo de Belén, s/n. 47011 \\ Valladolid \\ monica.ruiz.gonzalez@alumnos.uva.es
}

Recepción: 25 de enero de 2016

Fecha de aceptación definitiva: 4 de agosto de 2016

RESUMEN: Es evidente que las personas con doble discapacidad sensorial: sordociegas, presentan necesidades especiales para conseguir la integración. Ahora bien, determinar cuáles son los apoyos que necesitan estas personas para llevar a cabo una vida autónoma e integrarse socialmente sigue siendo un reto. Nos proponemos aquí descubrir qué factores sociales, contextuales y familiares influyen en la adquisición de la autonomía funcional de las personas con sordoceguera (PCS en lo sucesivo), en orden a conseguir estrategias eficaces que coadyuven a su integración. Dada la naturaleza de nuestro objetivo, se confiere gran importancia al discurso de las PCS y a su contexto y se aboga por la concepción de la discapacidad como interacción entre sujeto y entorno y no solo como la circunstancia personal, es decir, el énfasis se pone en cómo el entorno favorece/dificulta la adquisición de la autonomía y la integración.

Este artículo se centra en presentar el estado de la cuestión, concluyéndose, por un lado, que la sordoceguera es una discapacidad única con un carácter heterogéneo y, por otro, la escasa atención que las PCS han recibido hasta ahora, respondiendo en gran parte dicha escasez a su invisibilidad.

Palabras Clave: autonomía; integración; personas con sordoceguera; heterogeneidad; atención; invisibilidad.

AвsтRAcт: It is clear that people with dual sensory disability: deafblindness, have special needs for integration. Now, determine what supports they need to live an 
independent life and to be socially integrated remains a challenge. We propose here to discover what social, and family contextual factors influence the acquisition of the functional autonomy of deafblind people (PCS hereinafter), in order to get effective strategies that contribute to their integration. Given the nature of our goal, great importance is conferred to the discourse of PCS and its context. It advocates considering disability as an interaction between subject and environment, not only as personal circumstances. Indeed, the emphasis is on how the environment helps / hinders the acquisition of autonomy and integration.

This article focuses on the present state of affairs, concluding on one hand, deafblindness is a unique disability with a heterogeneous character, and secondly, the lack of attention that the PCS have received so far, largely due to its invisibility.

KEYWORDS: autonomy; integration; people with deafblindness; heterogeneity; attention; invisibility.

\section{Introducción}

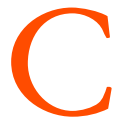

OMO PASARA CON LAS PERSONAS CON DISCAPACIDAD hace solo unas décadas en España, las PCS siguen sin recibir una atención que dé respuesta a sus necesidades. Sin una toma de contacto con personas que presentan sordoceguera, a priori, la mayoría de personas podrían pensar que una PCS (dado lo limitante que es carecer de dos sentidos de forma simultánea) difícilmente puede llevar una vida autónoma, sin embargo, mi labor profesional como trabajadora social de servicios sociales básicos me ha permitido tomar contacto con PCS y esta experiencia, a su vez, me ha permitido descubrir las enormes diferencias que en cuanto a autonomía funcional existen entre unos y otros sujetos. Por tanto, cabe interrogarse acerca de los factores que influyen en el desarrollo de la autonomía, es decir, cómo personas que, partiendo de un mismo diagnóstico, alcanzan niveles de autonomía tan dispares; tal y como apunta la Clasificación Internacional del Funcionamiento, de la Discapacidad y de la Salud -CIF, 2001- el diagnóstico de una enfermedad no es suficiente para describir el funcionamiento de un individuo.

Para conseguir descubrir estos factores, se aboga por una metodología cualitativa, teniendo como primer eje central el enfoque de las capacidades; este enfoque "concibe cada persona como un fin en sí misma y no se pregunta solamente por el bienestar total o medio, sino también por la oportunidades disponibles para cada ser humano" (Nussbaum, 2012: 38); aplicado a este colectivo, se trata de comprender a la PCS como sujeto con potencialidades, a partir de las cuales, y junto con los medios adecuados, puede llegar a realizarse y llevar una vida de calidad. Se trata de partir de un diagnóstico que se base, tal y como plantean Guthrie y Jeffrey (2013), no solo en las altas necesidades del colectivo de PCS, sino también en sus altas potencialidades. Como segundo eje central, se aboga por el enfoque de la calidad de vida, ya que este modelo pone el acento en el contexto, en la importancia de los factores contextuales para posibilitar el bienestar de sus miembros, de todos sus miembros. Nos interesa aquí destacar la línea de investigación de autores como 
Schalock y Verdugo (2003), que señalan la importancia que los factores contextuales tienen en la calidad de vida de los individuos y, además, destacan la ventaja que estos factores tienen sobre otros, ya que son factores sobre los que se puede actuar a través de programas o políticas de actuación. El enfoque se adapta a nuestro estudio, ya que también parte de la definición de la discapacidad como la interacción entre la persona y su entorno.

A partir de este marco metodológico, el objetivo que nos proponemos aquí se centra en facilitar los procesos de integración social de personas con sordoceguera. No obstante, uno de los objetivos específicos y necesarios para conseguir dicho propósito es conocer lo que ya existe con objeto de determinar el estado actual de la sordoceguera y detectar las debilidades y potencialidades que existen en la atención a las PCS. Lo que se pretende ofrecer a continuación es la delimitación de la sordoceguera: definición, causas, características, así como su tratamiento normativo y su repercusión en los servicios de atención.

\section{La sordoceguera: delimitación}

¿Qué es la sordoceguera? De forma intuitiva, podríamos contestar que una persona es sordociega cuando siendo ciega es también sorda, de tal forma que le es difícil -cuando no imposible- comunicarse con los demás con normalidad. Sin embargo, no todas las PCS son totalmente ciegas y sordas, las hay que presentan restos visuales y/o auditivos -aunque no siempre son funcionales-. En todo caso, el efecto de incomunicación y desconexión con el mundo que produce la combinación de las dos deficiencias es tal que la PCS tiene graves dificultades para acceder a la información, a la educación, a la capacitación profesional, al trabajo, a la vida social y a las actividades culturales.

Tal y como recoge Jarrold (2014), quien a su vez se basa en la definición noruega de sordoceguera, ésta es "una discapacidad distinta y singular que afecta a la vista y al oído; es diferente de las discapacidades separadas de ceguera y sordera. Sordoceguera no se refiere solo a ceguera y sordera profunda, sino a cualquier grado de deficiencia dual-sensorial” (p. 10). Efectivamente, existe un consenso generalizado a la hora de definir la sordoceguera como una discapacidad única, consistente en la combinación de la deficiencia visual y la auditiva, produciendo dicha combinación grandes dificultades en lo que respecta al acceso a la información, a la comunicación y a la movilidad. Ahora bien, esta idea casi obvia sobre quién es sordociego contrasta con la dificultad real para determinar cuantitativamente cuál es el grado de deficiencia visual que, combinado con determinado nivel de deficiencia auditiva, colocan a la persona en la situación de incomunicación que la convierte en sordociega. Los parámetros que definen una deficiencia visual o una deficiencia auditiva son diversos, y cada uno de ellos tiene una medida y un modo de medirse. Concretar qué combinación numérica determina la realidad funcional de incomunicación es imposible, aun sin tener en cuenta otras variables individuales (Álvarez, 2004: 136). 
Este hecho lleva a reflexionar sobre la dificultad real para determinar cuantitativamente cuál es el grado de deficiencia visual que, combinado con determinado grado de deficiencia auditiva, convierte a la persona en sordociega. En este sentido conviene además tener en cuenta que la existencia de restos sensoriales no siempre implica su uso, ya que pueden no ser funcionales. Por esta razón, la Deafblind International (DbI en lo sucesivo) propone que lo que defina la condición de sordoceguera sea determinado por la situación funcional derivada de la dificultad comunicativa de la persona (con el apoyo en los datos cuantitativos que avalen la pérdida sensorial). Los expertos en sordoceguera entienden que es más importante atender a cómo afecta la combinación de las pérdidas sensoriales a la vida de la persona; es decir, si esta combinación afecta funcionalmente a la persona en su movilidad, en su comunicación, en sus relaciones, etc., estaremos ante una persona sordociega, pero no podremos afirmarlo porque tenga una visión residual $\mathrm{X}$ combinada con una pérdida auditiva $Y$.

\section{Heterogeneidad de la sordoceguera: características}

Todo este debate nos conduce a una de las cuestiones más centrales de esta discapacidad: su heterogeneidad. Heterogeneidad en varios sentidos: por un lado, siguiendo con lo anterior, existen personas que a iguales pérdidas sensoriales tienen diferente grado de autonomía (la funcionalidad del sujeto no depende únicamente de la patología de salud que presente). Por otro lado, heterogeneidad en cuanto a la etiología, el momento de aparición de los déficits sensoriales (no es lo mismo nacer siendo sordociego que ser diagnosticado en la edad adulta), el orden (no es igual ni tiene las mismas consecuencias en el aprendizaje empezar siendo sordo y después ciego, que al revés).

A continuación veremos con mayor detenimiento las cuestiones más fundamentales relacionadas con la heterogeneidad de la sordoceguera.

\section{La etiología y el momento en que se producen las deficiencias sensoriales}

La sordoceguera no tiene una única causa que la origine, las causas que hacen que una persona sea sordociega pueden ser múltiples y producirse en diferentes momentos de la vida. Cuando los problemas de audición y visión se producen en el nacimiento o durante los dos primeros años de vida del sujeto, estamos ante personas con sordoceguera congénita (Ảlvarez, 2004). Si los motivos responsables de la pérdida de audición aparecen después del segundo año de vida (período que se considera vital para la adquisición del lenguaje -sordera postlocutiva-) y/o los responsables de la visión no están presentes en el nacimiento, se habla en general de sordoceguera adquirida (Álvarez, 2004; Puig, 2004). Este hecho es crucial, ya que determinará el lenguaje y la forma de comunicar y relacionarse de la persona (las personas que presentan en primer lugar la pérdida de audición aprenden el lenguaje de signos, mientras que las 
que presentan en primer lugar la deficiencia visual aprenden el lenguaje oral). Este hecho explica en parte que existan distintos tipos de sordoceguera y las características de esta discapacidad combinada.

Las principales causas que generan sordoceguera congénita son la prematuridad, la embriopatía rubeólica y el síndrome de Charge (Hernández y Peters, 2008). En cuanto a la prematuridad, hay que destacar que los niños que nacen de forma prematura tienen un riesgo alto de presentar problemas visuales y auditivos. Existen dos problemas que suelen darse de forma muy precoz: la retinopatía del prematuro (antes llamada fibroplasia retrolental), que puede provocar graves alteraciones visuales, incluso la ceguera, y la sordera neurosensorial (los niños prematuros están entre los grupos de más riesgo de padecer sordera). Un factor añadido es que estos niños, frecuentemente, presentan otros problemas graves de salud, por lo que sus déficits sensoriales no son atendidos con la rapidez deseable, quedando éstos en un segundo plano. La rubéola es una enfermedad viral habitualmente autolimitada y leve que afecta mayoritariamente a los niños. En el caso de una mujer embarazada, si la infección rubeólica se produce durante los primeros meses de gestación, se puede producir la embriopatía rubeólica, lo cual puede repercutir en que el niño nazca con diversos problemas, ya que, a diferencia del organismo materno en el que las defensas impiden que produzca daños importantes, el embrión pequeño apenas tiene defensas frente al virus (cuanto menor es la gestación del embrión, mayores son los daños que puede causar la infección). La sordera es muy frecuente entre los niños con rubéola congénita, así como la asociación de problemas visuales graves con la sordera, por lo que la sordoceguera es así mismo frecuente entre los niños con embriopatía rubeólica. El síndrome de Charge fue descrito por primera vez en 1979, si bien no se adoptó como acrónimo hasta 1981. CHARGE es la designación diagnóstica para un grupo de malformaciones congénitas que incluye un conjunto de anomalías con repercusión en la vista y el oído, muy variable de un caso a otro; cada una de las letras de la palabra CHARGE designa una anomalía distinta: $\mathrm{C}$ : carencia de partes del iris o la retina, $\mathrm{H}$ : defectos del corazón (soplo cardíaco, persistencia del conducto arterioso, defectos septales), A: atresia coanal, R: retraso en el crecimiento físico y/o en el sistema nervioso central, G: hipoplasia genital, E: deformaciones del oído (malformaciones del oído, frecuentemente acompañadas por pérdidas auditivas significativas). La mayoría de los niños con síndrome de CHARGE suelen presentar sordoceguera, padeciendo así mismo estos niños problemas de hipotonía y de pérdida de equilibrio. Como resultado de todo ello se producen retrasos en el lenguaje, en el desarrollo motor grueso, en el entendimiento del entorno y en las habilidades sociales. Muchos de los problemas de comportamiento de los niños con síndrome de CHARGE se derivan de sus discapacidades visuales y auditivas, que no son adecuadamente atendidas.

En cuanto a las principales causas que generan sordoceguera adquirida destacan dos: el síndrome de Usher y el síndrome Wolfram o de Dimoad (Álvarez, 2004). Si bien ambas enfermedades son de origen congénito, sus síntomas aparecen durante el transcurso de la vida, no en el momento del nacimiento. El síndrome de Usher fue descrito por primera vez en 1888. Este síndrome es un estado de sordera bilateral 
acompañado de una pérdida de visión progresiva, producida por una retinosis pigmentaria que afecta, de acuerdo a los estudios llevados a cabo en otros países, al 50\% de la población con sordoceguera ${ }^{1}$. Este síndrome se transmite genéticamente y exige, para que se manifieste, que padre y madre sean portadores del gen responsable. Hay diferentes tipos de síndrome de Usher, pero principalmente se habla de los tres tipos siguientes:

- Síndrome de Usher Tipo I: se manifiesta una deficiencia auditiva profunda al nacer. Los síntomas de la retinosis pigmentaria suelen ser detectados en torno a la adolescencia o preadolescencia. Su sistema de comunicación es la lengua de signos (primero en el aire y, posteriormente, apoyada en el tacto). Estas personas suelen presentar dificultades en el equilibrio. Es el tipo más frecuente.

- Síndrome de Usher Tipo II: al nacer, la deficiencia auditiva no suele manifestarse y la deficiencia visual no es detectable. La afectación auditiva puede oscilar entre moderada y severa. Los síntomas de la retinosis pigmentaria suelen aparecer en torno a la adolescencia o preadolescencia. En general, hay un desarrollo normal del lenguaje. La pérdida auditiva es descrita como estable por los investigadores, así como la no existencia de problemas de equilibrio.

- Síndrome de Usher Tipo III: nacen sin manifestar problemas de visión ni audición. La aparición de los síntomas es más tardía que en el caso de las personas que padecen síndrome de Usher tipo II, tanto auditiva como visualmente. La pérdida de oído es progresiva y la inteligibilidad del habla se ve rápidamente afectada. Los síntomas de la retinosis pigmentaria son generalmente detectados antes que los de la deficiencia auditiva y la evolución de la retinosis es más rápida que en el síndrome de Usher tipo II.

El síndrome de Wolfram o de Dimoad (DIDMAOS) fue descrito por primera vez en 1938 por Wolfram, posteriormente fue investigado por otros estudiosos, que lo relacionaron con varias enfermedades (diabetes insípida, diabetes mellitus, atrofia óptica y sordera), de ahí que sea también conocido con el acrónimo DIDMAOS. Los afectados por el síndrome DIDMAOS manifiestan una atrofia óptica bilateral cuya edad de comienzo se encuentra entre los 2 y los 24 años (en la mayoría de los casos se manifiesta antes de los 15 años). La principal característica de este síndrome es la sordera neurosensorial bilateral y simétrica. Generalmente, el deterioro auditivo empieza durante la primera década de vida (se pasa de una pérdida suave a una moderada), en la segunda década se deteriora aún más y cuando llega a la tercera, la pérdida es muy intensa. La diabetes mellitus normalmente precede al inicio de la atrofia óptica y también a la detección de la pérdida auditiva. Normalmente la visión se deteriora de forma lenta.

Debido a la naturaleza progresiva de la pérdida visual del síndrome de Usher y Wolfram, es necesario tener en cuenta las posibles pérdidas posteriores al momento de la evaluación.

1 Dato proveniente de la Guia de Orientación en la Práctica Profesional de la Valoración Reglamentaria de la Situación de Dependencia en Personas con Sordoceguera. Ministerio de Sanidad, Política Social e Igualdad (s. f., p. 15). 


\section{Dimensiones a considerar en la sordoceguera}

A continuación, nos centraremos en las principales dimensiones que hacen que en esta población existan unas características diferenciales, que marquen su especificidad como discapacidad única (Puig, 2004). Como hemos referido anteriormente, la dificultad perceptiva de la PCS va a ser diferente según el tipo de pérdida sensorial que presente (Álvarez, 2004; Puig, 2004). El hecho de que la pérdida visual, la auditiva o ambas sean estables o tengan carácter progresivo; el efecto de que la pérdida auditiva se derive de un problema conductivo o neurosensorial; o que en el caso de la deficiencia visual lo afectado sea la agudeza, el campo o ambos son cuestiones determinantes para la PCS y su aprendizaje.

Análogamente, el grado de pérdida es así mismo determinante para el desarrollo y funcionamiento de la persona. El que la pérdida sea total en ambos sentidos; el que existan restos en los dos sentidos o que solo los haya en uno de ellos; y el que los restos sensoriales sean o no funcionales son cuestiones primordiales para el aprendizaje, inicial y posteriores, que va a tener la PCS presente (Álvarez, 2004; Puig, 2004). En esta misma línea, cabe destacar el orden de aparición de las limitaciones sensoriales. El momento de aparición del déficit auditivo influye esencialmente en el desarrollo de la comunicación y la adquisición del lenguaje (Hernández y Peters, 2008). Si la lesión de vista y oído se produce antes de que el niño alcance el estadio simbólico es mucho más difícil conseguir que desarrolle un sistema de comunicación y, por tanto, lenguaje (éste es el caso de niños con sordoceguera congénita, especialmente si no hay resto en ninguno de los sentidos). El orden de aparición de cada una de las deficiencias es un factor muy importante, porque, entre otros aspectos, condiciona el sistema de comunicación de la persona sordociega (especialmente cuando una de las dos deficiencias es congénita). Son muy distintos los casos de personas que nacen con discapacidad visual/ciegas y quedan sordas/con discapacidad auditiva a lo largo de su vida (conocen la lengua oral y se expresan oralmente) de aquellos casos en los que aparece la sordera en primer lugar -en el nacimiento o al poco de nacer- y después quedan ciegos/con graves deficiencias visuales (se expresan en lengua de signos). Si la persona ha visto y oído antes de quedarse sordociega se expresará oralmente, independientemente de que sea primero sorda y luego ciega.

Así mismo, es importante destacar la importancia que tiene si la persona presenta o no otras discapacidades. Algunas PCS padecen además de las pérdidas auditivas o visuales otras limitaciones, por ejemplo, en el caso de los niños afectados por rubéola, con frecuencia se encuentran además lesiones de corazón y lesiones neurológicas que condicionan su desarrollo. Cuando estas deficiencias comprometen más la vida del individuo, hace que las deficiencias sensoriales no sean atendidas con la rapidez deseable (Álvarez, 2004), todo ello conduce en muchos casos a la privación sensorial. En la mayoría de los casos, esta privación (debida a una intervención tardía) es la responsable de la existencia de déficits madurativos y cognitivos irreversibles. Por último, no puede desdeñarse la importancia que tiene para la PCS el ambiente en el que se desarrolla, su familia y entorno. La actitud de la familia y el entorno socioafectivo en el que se mueve la PCS es determinante para el desarrollo de la comunicación y conocimiento

(C) Ediciones Universidad de Salamanca / CC BY-NC-ND

Siglo Cero, vol. 47 (3), n. ${ }^{\circ}$ 259, 2016, julio-septiembre, pp. 29-45 
del mundo que le rodea (Hernández y Peters, 2008). El contexto familiar y sociocultural de la PCS condiciona el ambiente estimular y, por lo tanto, el desarrollo, capacidad y motivación para que la persona con sordoceguera se desenvuelva de manera más o menos autónoma. Dada la importancia de estas variables para la adquisición de la autonomía, es importante analizar su influencia como aspectos externos.

\section{Clasificación funcional de las personas con sordoceguera}

Como hemos referido, las PCS pueden clasificarse atendiendo al momento y al orden de aparición de las deficiencias sensoriales, sin embargo, existe otra forma de clasificación, que es la preferida por los profesionales que trabajan con las PCS. Tal y como hemos señalado anteriormente, la DbI y otras organizaciones que abogan por la defensa de las PCS defienden que la condición de sordoceguera sea determinada por la situación funcional derivada de la dificultad comunicativa de la persona (siendo dicha dificultad resultado de la combinación de la deficiencia visual y auditiva), ya que utilizar el criterio cuantitativo no permite establecer un límite claro a partir del cual afirmar que una persona es sordociega (es decir, no hay determinados valores que equivalgan a ser sordociego; personas con los mismos valores de deficiencia presentan grados de autonomía distintos). Así pues, existe otra forma de clasificar a esta población y es a través de su nivel de funcionamiento, distinguiéndose tres grupos (Álvarez, 2004; Hernández y Peters, 2008):

- Bajo nivel de funcionamiento

Se agrupa a los sujetos -independientemente de su edad- que tienen una comunicación limitada a aspectos básicos, por no alcanzar lo que Fravell (1977) denomina motivación cognitiva ${ }^{2}$.

El objetivo de la intervención será obtener una comunicación estructurada (tanto como las características de la persona permitan) y el desarrollo de unas habilidades básicas que permitan conseguir una autonomía personal acorde a sus posibilidades.

- Nivel medio de funcionamiento

En este grupo encontramos a niños, jóvenes y adultos capaces de interesarse por el mundo cognitivamente, de generar estrategias más o menos elementales para la resolución de problemas, de llevar una vida semiindependiente y de imitar signos convencionales, al menos ligados a necesidades primarias.

La intervención debe contemplar objetivos encaminados a desarrollar un sistema de comunicación, habilidades útiles en la vida diaria, habilidades sociales y estrategias que le permitan desarrollar una actividad laboral protegida cuando sus características lo permitan.

Es fundamental tener en cuenta la inclusión de las ayudas técnicas apropiadas en función de las características de la PCS.

2 Fravell describe la motivación cognitiva como el impulso/deseo infantil para interactuar y aprender sobre el entorno por la simple búsqueda de conocimiento. 
- Alto nivel de funcionamiento

Agrupa a PCS sin otro límite cognitivo que el derivado de la propia sordoceguera. Estos sujetos demuestran estrategias de resolución de problemas e intereses, todo lo cual parece indicar que son susceptibles de llevar una vida normalizada, si cuentan con el apoyo especializado necesario. La intervención ha de contemplar siempre la inclusión de las ayudas técnicas y tiflotécnicas necesarias. Visto lo anterior, puede apreciarse que el momento en que aparece la deficiencia (cuándo) y en qué orden, así como el nivel de funcionamiento del sujeto, determinan el modo en que esa persona aprende a comunicar ( $y$ sus aprendizajes posteriores), así pues:

\begin{tabular}{|l|l|l|l|}
\hline \multicolumn{4}{|c|}{ Tabla 1. Sistemas de comunicación de las PCS } \\
\cline { 2 - 4 } & \multicolumn{1}{|c|}{ Nivel bajo } & \multicolumn{1}{|c|}{ Nivel medio } & \multicolumn{1}{c|}{ Nivel alto } \\
\hline $\begin{array}{l}\text { Personas con } \\
\text { sordoceguera } \\
\text { congénita }\end{array}$ & $\begin{array}{l}\text { Receptiva y Expresiva: } \\
\text { Sistema de Signos } \\
\text { Naturales }\end{array}$ & $\begin{array}{l}\text { Receptiva y Expresiva: } \\
\text { Lengua de Signos }\end{array}$ & $\begin{array}{l}\text { Receptiva y Expresiva: } \\
\text { Lengua de Signos/ } \\
\text { Sistema Dactilológico }\end{array}$ \\
\hline $\begin{array}{l}\text { Personas sordociegas } \\
\text { con deficiencia } \\
\text { auditiva congénita } \\
\text { y pérdida de visión } \\
\text { adquirida }\end{array}$ & $\begin{array}{l}\text { Receptiva y Expresiva: } \\
\text { Sistema de Signos } \\
\text { Naturales }\end{array}$ & $\begin{array}{l}\text { Receptiva y Expresiva: } \\
\text { Lengua de Signos }\end{array}$ & $\begin{array}{l}\text { Receptiva y Expresiva: } \\
\text { Lengua de Signos/ } \\
\text { Sistema Dactilológico }\end{array}$ \\
\hline $\begin{array}{l}\text { Personas sordociegas } \\
\text { con deficiencia } \\
\text { visual congénita y } \\
\text { pérdida de audición } \\
\text { adquirida }\end{array}$ & $\begin{array}{l}\text { Receptiva: Sistema de } \\
\text { Signos Naturales } \\
\text { Expresiva: Palabras } \\
\text { aisladas }\end{array}$ & $\begin{array}{l}\text { Receptiva: Sistema } \\
\text { Dactilológico } \\
\text { Expresiva: Lenguaje } \\
\text { oral }\end{array}$ & $\begin{array}{l}\text { Receptiva: Sistema } \\
\text { Dactilológico } \\
\text { combinado con signos } \\
\text { Expresiva: Lenguaje } \\
\text { oral }\end{array}$ \\
\hline $\begin{array}{l}\text { Personas con } \\
\text { sordoceguera } \\
\text { adquirida }\end{array}$ & $\begin{array}{l}\text { Receptiva: Sistema de } \\
\text { Signos Naturales } \\
\text { Expresiva: Palabras } \\
\text { aisladas }\end{array}$ & $\begin{array}{l}\text { Receptiva: Sistema } \\
\text { Dactilológico } \\
\text { Expresiva: Lenguaje } \\
\text { oral }\end{array}$ & $\begin{array}{l}\text { Receptiva: Sistema } \\
\text { Dactilológico/Escritura } \\
\text { en palma } \\
\text { Expresiva: Lenguaje } \\
\text { oral }\end{array}$ \\
\hline
\end{tabular}

Fuente: Elaboración propia a partir de Álvarez en GómEz y Romero (2004: 152-158).

\section{Tratamiento normativo de la sordoceguera y su repercusión en la atención a PCS}

A la vista de lo expuesto se constata que la sordoceguera es una discapacidad específica que requiere servicios especializados para la adecuada atención a las personas que la presentan, siendo necesario que estos recursos sean capaces de adaptarse a la heterogeneidad que la caracteriza, dando respuesta a todas las formas en que puede presentarse la sordoceguera. Tal y como recoge Jarrold (2014), es necesario "el reconocimiento oficial de la sordoceguera como discapacidad singular en todos los 
$\operatorname{estados}^{3}$ (4), principalmente para asegurar que los derechos y las vidas de las personas con sordoceguera sean reconocidos” (p. 18). La creación de recursos se produce tras el reconocimiento de derechos, por tanto, para conocer y entender la atención que reciben las PCS se hace necesario llevar a cabo una revisión normativa. A continuación se destacan las normas en las que aparece de forma explícita la sordoceguera. En el ámbito europeo, destacan:

- Proposición no de Ley 161/000800, aprobada por la Comisión No Permanente para Políticas Integrales de la Discapacidad del Parlamento español, el 29 de noviembre de 2005 (BOCG, n. $\left.{ }^{\circ} 43,29 / 11 / 2005\right)$ en la que se reconoce la sordoceguera como una discapacidad única, con entidad propia y necesidades específicas, que afecta gravemente las habilidades diarias necesarias para poder llevar una vida mínimamente autónoma.

- Declaración 1/2004 del Parlamento Europeo sobre los derechos de las personas sordociegas. Esta declaración recoge que las personas sordociegas deberían tener los mismos derechos que los demás ciudadanos de la Unión Europea y que estos derechos deberían garantizarse mediante una legislación adecuada en cada Estado miembro, haciendo alusión directa a su derecho a participar en la vida pública, a trabajar y tener acceso a la formación, a recibir cuidados sociales y sanitarios centrados en la persona y a recibir una ayuda personalizada.

En el ámbito estatal, en varias normas se recoge el derecho de las PCS al aprendizaje, conocimiento y uso de las lenguas de signos españolas y de los medios de apoyo a la comunicación oral, destacando:

- El Real Decreto Legislativo 1/2013, de 29 de noviembre, por el que se aprueba el Texto Refundido de la Ley General de derechos de las personas con discapacidady de su inclusión social (BOE n. ${ }^{\circ} 289$ de 03/12/2013), donde se hace alusión al reconocimiento que existe en la Ley 27/2007, de 23 de octubre, por la que se reconocen las lenguas de signos españolas y se regulan los medios de apoyo a la comunicación oral de las personas sordas, con discapacidad auditiva y sordociegas (BOE n. ${ }^{\circ} 255$ de 24/10/2007), sobre el derecho de las personas sordociegas al aprendizaje, uso y conocimiento de las lenguas de signos y de los distintos medios de apoyo a la comunicación oral, como factor esencial para su inclusión social.

- Real Decreto 422/2011, de 25 de marzo, por el que se aprueba el Reglamento sobre las condiciones básicas para la participación de las personas con discapacidad en la vida política y en los procesos electorales (BOE n. ${ }^{\circ} 76$ de 30/03/2011). Se hace la siguiente alusión directa a las personas sordociegas: "Los servicios de atención telefónica que, en su caso, la Administración General del Estado ponga en marcha serán accesibles para todas las personas con discapacidad, en especial se atenderán las necesidades de las personas sordas, con discapacidad auditiva y sordociegas" (BOE n. ${ }^{\circ} 76$ de 30/04/2011, 33046).

- La Ley 27/2007, de 23 de octubre, por la que se reconocen las lenguas de signos españolas y se regulan los medios de apoyo a la comunicación oral de las personas

3 Así se recoge en el estudio European Deafblind Indicators. En dicho estudio han participado 27 países de la UE y pretende ofrecer una perspectiva global de los servicios, soporte y derechos legales de las PCS en Europa. 
sordas, con discapacidad auditiva y sordociegas (BOE n..$^{\circ} 25$ de 24/10/2007). La presente Ley tiene por objeto reconocer y regular la lengua de signos española como lengua de las personas sordas, con discapacidad auditiva y sordociegas en España que libremente decidan utilizarla, así como regular los medios de apoyo a la comunicación oral destinados a las personas sordas, con discapacidad auditiva y sordociegas. En su disposición adicional sexta recoge: “el Ministerio de Trabajo y Asuntos Sociales realizará un estudio en el que se determine el número de personas con sordoceguera, sus condiciones de vida y su ubicación geográfica, a efectos de determinar los centros de referencia que se deberán crear, así como el establecimiento de recursos más acordes con las especiales necesidades de este colectivo" (BOE n. ${ }^{\circ} 255$ de 24/10/2007, 43259).

No obstante lo expresado en esa disposición, dicho estudio sigue sin llevarse a cabo, por lo que sigue sin conocerse el número de personas con sordoceguera, sus condiciones de vida ni su ubicación geográfica (significando esto, como ya se ha mencionado anteriormente, una de las principales dificultades de inserción para este colectivo). La necesidad de llevar a cabo este censo es reconocida así mismo por Europa, tal y como recoge Jarrold (2014): “Los censos nacionales deben preguntar a la gente de manera rutinaria si tienen problemas de vista o de oído para que podamos entender mejor el alcance y las características de la sordoceguera” (p. 18).

La primera cuestión que destaca al hacer la revisión normativa es que las referencias legales sobre sordoceguera son escasas y recientes, lo cual refleja a su vez la escasa visibilidad y el desconocimiento que sobre este colectivo se tiene. Como hemos visto, las referencias explícitas a las PCS son excepcionales y si bien en el ámbito europeo la sordoceguera está reconocida como una discapacidad específica, que necesita de ayuda así mismo específica y de profesionales especializados, en España únicamente encontramos el reconocimiento de apoyos específicos para las PCS en la Ley 27/2007, de 23 de octubre, por la que se reconocen las lenguas de signos españolas y se regulan los medios de apoyo a la comunicación oral de las personas sordas, con discapacidad auditiva y sordo-ciegas (BOE n. ${ }^{\circ} 255$ de 24/10/2007) y en el Real Decreto Legislativo 1/2013, de 29 de noviembre, por el que se aprueba el Texto Refundido de la Ley General de derechos de las personas con discapacidad y de su inclusión social (BOE 03/12/2013), en ambas normas se reconoce el derecho de las personas sordociegas al aprendizaje, uso y conocimiento de las lenguas de signos y de los distintos medios de apoyo a la comunicación oral, como factor esencial para su inclusión social y si bien este reconocimiento supone un avance, es insuficiente para cubrir las necesidades de atención de las PCS.

La segunda cuestión que conviene destacar es que, al margen de estas normas donde aparece recogida expresamente la sordoceguera, existen otras donde debiera aparecer reflejada y no lo hace, siendo éste el caso de todas aquellas normas donde se alude a la especificidad de discapacidades y esta discapacidad no aparece recogida, como por ejemplo, en el Real Decreto 1612/2007, de 7 de diciembre por el que se regula un procedimiento de voto accesible que facilita a las personas con discapacidad visual el ejercicio de derecho de sufragio (BOE n. 294 de 08/12/2007), esta norma debería 
contemplar a las PCS, sin embargo, solo se alude a las personas ciegas o gravemente limitadas visualmente y, por tanto, solo se contempla la utilización del Braille y, como se ha comprobado, no todas las PCS conocen y utilizan este lenguaje como sistema de comunicación -solo aquellas que fueron ciegas y no sordas durante algún tiempo-. Tampoco recoge de forma específica a las PCS, y debiera hacerlo, la Orden PRE 11822/2006, de 9 de junio, por la que se establecen criterios generales para la adaptación de tiempos adicionales en los procesos selectivos para el acceso al empleo público de personas con discapacidad (BOE n. ${ }^{\circ} 140$, de 13/06/2006), ya que en esta orden se recogen las adaptaciones necesarias para que las personas con discapacidad puedan realizar en igualdad de condiciones las pruebas selectivas, contemplándose la concesión de un tiempo adicional para la realización de los ejercicios correspondientes en función del tipo de discapacidad que se presente. Sería oportuno y necesario encontrar referencia específica a las personas con sordoceguera, ya que sus necesidades son particulares y distintas a las de las personas sordas y a las de las personas ciegas. Sin embargo, no se recoge la sordoceguera en el anexo donde aparecen los tiempos adicionales en función de la discapacidad que se presente, lo cual se considera un agravio comparativo para este colectivo (sí aparecen contempladas la ceguera, la sordera y la sordomudez, con los tiempos adicionales para cada una de las discapacidades, pero no la sordoceguera).

La tercera cuestión a señalar es que, si bien en determinadas normas se reconoce un derecho, en la práctica ese derecho no se está garantizando y haciendo efectivo, como, por ejemplo, en la Ley 33/2011, de 4 de octubre, General de Salud Pública ( $B O E$ n. ${ }^{\circ} 240$, de 05/10/2011), que recoge la atención específica a las necesidades de las personas con discapacidad como principio regidor de la ley y alude al derecho a la no discriminación y a la información y accesibilidad y, sin embargo, las PCS no pueden hacer efectivo el derecho a la información y accesibilidad a la misma ya que, desde el ámbito público, no existen a disposición de estas personas intérpretes que hagan efectivo este derecho (en la práctica, estas personas recurren a organizaciones del tercer sector para poder contar con un intérprete que les acompañe a las consultas médicas) o en el Real Decreto 1494/2007, de 12 de noviembre, por el que se aprueba el Reglamento sobre las condiciones básicas para el acceso de las personas con discapacidad a las tecnologías, productos y servicios relacionados con la sociedad de la información y medios de comunicación social (BOE n. $^{\circ} 279$, de 21/11/2007), ya que si bien se recoge que "la información disponible en las páginas de Internet de las administraciones públicas deberá ser accesible a las personas mayores y personas con discapacidad, con un nivel mínimo de accesibilidad que cumpla las prioridades 1 y 2 de la Norma UNE 139803:2004” (p. 47571) y así mismo, que las citadas páginas de Internet “tendrán en cuenta lo dispuesto en la Ley 27/2007, de 23 de octubre, por la que se reconocen las lenguas de signos españolas y se regulan los medios de apoyo a la comunicación oral de las personas sordas, con discapacidad auditiva y sordociegas” (p. 47571), las PCS no pueden acceder a la información de dichas páginas por no disponer de los medios necesarios para ello.

La escasa presencia de la PCS en la normativa es indicativa de la escasa visibilidad que estas personas tienen como colectivo; en este sentido, conviene destacar que se desconoce cuántas personas están afectadas por la doble discapacidad en España, ya

(C) Ediciones Universidad de Salamanca / CC BY-NC-ND

Siglo Cero, vol. 47 (3), n. ${ }^{\circ}$ 259, 2016, julio-septiembre, pp. 29-45 
que no existe un censo ni datos oficiales sobre el número de PCS que hay en España -si bien, según se recoge en algunos manuales, se estima que haya unas 15 personas afectadas por cada 100.000 habitantes ${ }^{4}$ y explica, a su vez, la escasez de recursos públicos dirigidos a su atención. El número de personas que pueden enfrentarse a problemas asociados con el oído y la vista en Europa se cifra en alrededor de tres millones, según recoge Jarrold (2014: 10).

Todo lo anterior evidencia una realidad: en España, sigue sin existir una red pública de recursos suficiente para PCS. No obstante, cabe destacar el avance que ha supuesto para la atención a las personas con situaciones de dependencia, y en concreto para las PCS, la Ley 39/2006, de 14 de diciembre, de Promoción de la Autonomía Personal y Atención a las personas en situación de dependencia (BOE n. ${ }^{\circ} 299$, de 15/12/2006), ya que dicha norma recoge el derecho a la promoción de la autonomía personal y atención a las situaciones de dependencia como derecho subjetivo, con la consiguiente creación de un sistema para la autonomía y atención a las situaciones de dependencia. El garante de dicho sistema es el Estado, que proporciona y garantiza un contenido mínimo común de derechos para todos los ciudadanos en cualquier parte del territorio del Estado español. Así mismo, aparece la figura del asistente personal, como profesional que colabora con la persona en situación de dependencia posibilitando que ésta disfrute de una vida independiente, promocionando su autonomía personal, siendo este recurso uno de los más solicitados por las PCS. Todo ello supone un avance, no obstante, insuficiente para cubrir las necesidades de atención de la PCS.

Las PCS requieren servicios especializados, personal específicamente formado para su atención y métodos especiales de comunicación para poder hacer frente a las actividades de la vida diaria. Las principales demandas de la PCS se centran en la participación y la comunicación, tanto receptiva como expresiva, y estos apoyos los obtienen fundamentalmente a través de asociaciones y organizaciones del Tercer Sector. Son estas entidades las que les proporcionan guías intérpretes y mediadores que les acompañan y les capacitan para ser más autónomos en su vida diaria (les enseñan a manejar el bastón guía, a utilizar las TIC, etc.), al tiempo que se les ofrece una ocupación del tiempo a través de actividades diversas: talleres, salidas, etc. Este hecho rompe con la tendencia a considerar a las PCS como receptoras de apoyo en lugar de como participantes activos en la sociedad. Según recoge Hersh (2013), basándose en un estudio llevado a cabo en seis países diferentes, las PCS (independientemente del país al que pertenecen) están interesadas en participar y contribuir en la sociedad, especialmente a través de las organizaciones de personas sordociegas. No obstante, Hersh señala en ese mismo trabajo que sí existen diferencias entre los países participantes en cuanto a los apoyos disponibles para las PCS. En la atención a la sordoceguera en España, destaca la labor realizada por las siguientes organizaciones y asociaciones:

4 Dato obtenido por estadística comparada con otros países, así se recoge en la Guía de Orientación en la Práctica Profesional de la Valoración Reglamentaria de la Situación de Dependencia en Personas con Sordoceguera. Ministerio de Sanidad, Política Social e Igualdad (s. f., p. 9) y en Gómez y Romero (Coords.) (2004: 159). 
- FESOCE: Federación Española de Sordoceguera.

- ONCE: FOAPS: Fundación Once para las personas con sordoceguera.

- ASOCIDE: Asociación de Sordociegos de España (con Delegaciones en Andalucía, Aragón, Canarias, Castilla y León, Cataluña, Comunidad Valenciana, Comunidad de Madrid y País Vasco). En Castilla y León existe, así mismo, la asociación ASOCyL.

- APASCIDE: Asociación Española de Familias de Personas con Sordoceguera. Cabe destacar que la creación del centro "Santa Ángela de la Cruz”, único centro específico de referencia estatal para personas sordociegas, fue promovido por esta asociación (dicho centro se encuentra en la localidad sevillana de Salteras y fue inaugurado en el año 2010).

\section{Algunas conclusiones}

Atendiendo a todo lo visto hasta ahora, puede presentarse un avance con las conclusiones alcanzadas hasta el momento. En primer lugar, cabe destacar que la sordoceguera es un fenómeno complejo y heterogéneo, ya que las PCS pueden presentar distintas pérdidas sensoriales, estas pérdidas pueden producirse en diferentes momentos, puede darse primero la limitación auditiva y posteriormente la visual o viceversa, puede haber personas que a iguales combinaciones de pérdidas sensoriales presenten distintos niveles de autonomía funcional, etc. Todo ello hace que la realidad de las PCS sea muy diversa y compleja, puesto que es necesario que existan respuestas para cada una de las formas en que la sordoceguera puede presentarse. Por otro lado, como es sabido, las respuestas a las necesidades de las personas con discapacidad han estado -y continúan estando- directamente vinculadas a los derechos reconocidos, este hecho en el caso de la PCS explica la forma en la que se ha respondido hasta ahora a sus necesidades, ya que su presencia en la normativa es escasa y reciente, tanto en el ámbito europeo como en el estatal, lo cual ha repercutido en una escasa atención. No obstante lo anterior, es cierto que se ha producido cierto avance en el reconocimiento de derechos de las PCS, este avance se refleja en alusiones directas en ciertas normas o en la creación de determinados recursos, como la figura del asistente personal en la Ley 39/2006, de 14 de diciembre, de Promoción de la Autonomía Personal y Atención a las personas en situación de dependencia (BOE n. ${ }^{\circ} 299$, de 15/12/2006), aunque dicho reconocimiento en el papel no siempre se ve traducido en la dotación de recursos, recursos que son imprescindibles para hacer efectivos tales derechos. Es incuestionable que para crear dichos recursos debe atenderse a la especificidad de la sordoceguera, que hace necesaria su atención a través de profesionales específicamente formados en sistemas de comunicación (siendo ésta es una de las principales demandas de las PCS, a través de guías intérpretes o mediadores). Otra de las cuestiones que ha quedado patente es el gran desconocimiento que se tiene sobre la sordoceguera y la escasa visibilidad de las personas que la presentan, esta afirmación se apoya en cuestiones tan contundentes como la no existencia de un censo ni datos oficiales sobre el número de personas sordociegas 
que hay en España, la reciente y escasa presencia de las personas sordociegas en la normativa o en la escasez de recursos dirigidos a su atención (fundamentalmente prestados a través del Tercer Sector). A nivel internacional encontramos así mismo referencias que avalen esta afirmación, como el estudio llevado a cabo por Galvão y Miranda (2013), en la ciudad brasileña de Salvador de Bahía. Estas autoras llevaron a cabo un estudio cualitativo con cuatro estudiantes con sordocegura y establecieron en sus conclusiones que las necesidades educativas de estos alumnos son ignoradas, lo que comporta su invisibilidad en la escuela.

Por todo lo expuesto se considera suficientemente justificado el interés científico y social de llevar a cabo una tesis doctoral sobre sordoceguera. Nos proponemos aquí orientar el trabajo de dicha tesis hacia: el aumento del conocimiento científico sobre la sordoceguera, siguiendo la línea de los autores científicos que investigan sobre esta problemática; la profundización en el conocimiento de las personas con sordoceguera: características, necesidades, potencialidades y expectativas de vida; la colaboración en tratar de hacer visibles a las personas con sordoceguera; la orientación en la creación de recursos de apoyo para personas con sordoceguera, a partir de las necesidades detectadas, así como hacia el servir de guía para futuros planes y proyectos de integración para personas con sordoceguera.

\section{Referencias bibliográficas}

Álvarez, D. (2004). La sordoceguera. Un análisis multidisciplinar. En P. Gómez y E. Romero (Coords.), La sordoceguera: una discapacidad singular (pp. 135-159). Madrid: ONCE.

Ardura, A. J. (2000). Ocio, calidad de vida y discapacidad. En M. L. Setién (Coord.), Actas de las Cuartas Jornadas de la Cátedra de Ocio y Minusvalias. En Sordoceguera: ocio y tiempo libre (pp. 87-92). Bilbao: Universidad de Deusto.

Bigby, C. y Frawley, P. (2010). Social work and intellectual disability: Working for change. London: Palgrave MacMillan.

Campello, L. (2007). La Dependencia en el contexto actual. Santiago de Compostela: Zabaleta Beraza, Rodríguez González y Muradás López (eds.).

Casado, D. (2006). Aproximación a la dependencia funcional. Documentación Social, 141, 11-22.

Casado, D. y Fernández Pinar, L. (2013). Objetivos y medios idóneos relativos a la dependencia funcional. Zerbitzuan Revista de Servicios Sociales, 54, 157-170.

CAyo, L. (2006). La discapacidad y las situaciones de dependencia, una aproximación conceptual y estadística. Revista del Ministerio de Trabajo y Asuntos Sociales.

Dejong, G. (1981). Environmental accesibility and independent living outcomes. Directions for disability policy and research. Michigan: Michigan State University, UCIR.

Díaz Jiménez, R. M. (2011). Trabajo social y discapacidad intelectual en centros residenciales $y$ de día en Andalucía. Aproximación desde la Teoría Fundamentada. Tesis de doctorado. Universidad Pablo de Olavide.

Dubet, F. (2012). Repensar la justicia social. Buenos Aires: Siglo XXI.

Egea, C. y SARAbia, A. (2004). Visión y modelos conceptuales de la discapacidad. Revista Polibea, 73, 29-42.

Ferreira, M. (2010). Por una Sociología de la Discapacidad. Revista Política y Sociedad, 47.

(C) Ediciones Universidad de Salamanca / CC BY-NC-ND

Siglo Cero, vol. 47 (3), n. ${ }^{\circ}$ 259, 2016, julio-septiembre, pp. 29-45 
Galvão, N. y Miranda, T. (2013). Atendimento educacional especializado para alunos com surdocegueira: um estudo de caso no espaço da escola regular. Revista Brasileira de Educação Especial, $19^{5}$ (1), 43-60.

Gómez, P. y Romero, E. (Coords.) (2004). La sordoceguera. Un análisis multidisciplinar. Madrid: ONCE.

Guthrie, D. y Poss, J. (2013). Development of a case-mix funding system for adults with combined vision and hearing loss. Bmc Health Services Research, 13. Recuperado de: http://sid. usal.es/20225/8-2-6.

Hernández, R. y Peters, S. F. (2008). Manual de atención al alumnado con necesidades específicas de apoyo educativo asociadas a la sordoceguera. En Manual de atención al alumnado con necesidades especificas de apoyo educativo derivadas de la discapacidad visual y sordoceguera (pp. 43-84). Sevilla: Junta de Andalucía, Consejería de Educación.

Hersh, M. (2013). Deafblind people, communication, independence, and isolation. Journal of Deaf Studies and Deaf Education, 18 (4), 446-463.

IMSERSO (s. f.). Guia de orientación en la práctica profesional de la valoración reglamentaria de la situación de dependencia en personas con sordo-ceguera. Madrid: IMSERSO.

Jarrold, K. (2014). European Deafblind Indicators. European Comission: European Deafblind Network (EDbN).

Nussbaum, M. (2012). Crear capacidades: propuesta para el desarrollo bumano. Barcelona: Paidós.

OMS (2011). Clasificación Internacional del Funcionamiento, de la Discapacidad y de la Salud. Madrid: Ministerio de Sanidad, Política Social e Igualdad.

Palacios, A. (2008). El modelo social de discapacidad: orígenes, caracterización y plasmación en la Convención Internacional sobre los Derechos de las Personas con Discapacidad. Madrid: CINCA.

Pantano, L. (2009). Nuevas miradas en relación con la conceptualización de la discapacidad. Condición y situación de discapacidad. En Visiones y Revisiones de la Discapacidad (pp. 73-97). México: Fondo de Cultura Económica.

Puig, M. V. (2004). Manual para la intervención y ajuste a la discapacidad visual. En J. CHECA et al. (Coords.), Intervención Psicológica para el Ajuste en Grupos Especificos de Población. Primera parte: sordoceguera (pp. 415-459). Madrid: ONCE.

Schalock, R. L. y Verdugo, M. Á. (2003). Calidad de vida: manual para profesionales de la educación, salud y servicios sociales. Madrid: Alianza.

\section{Referencias normativas}

Real Decreto Legislativo 1/2013, de 29 de noviembre, por el que se aprueba el Texto Refundido de la Ley General de derechos de las personas con discapacidad y de su inclusión social (BOE n. ${ }^{\circ} 289$ de 03/12/2013).

Ley 33/2011, de 4 de octubre, General de Salud Pública (BOE n. ${ }^{\circ}$ 240, de 05/10/2011).

Real Decreto 422/2011, de 25 de marzo, por el que se aprueba el Reglamento sobre las condiciones básicas para la participación de las personas con discapacidad en la vida política y en los procesos electorales (BOE n. ${ }^{\circ} 76$ de 30/03/2011).

5 El presente artículo forma parte del estudio, análisis e investigación que se está llevando a cabo sobre la sordoceguera, en el marco de la tesis doctoral de la autora.

(c) Ediciones Universidad de Salamanca / CC BY-NC-ND

Siglo Cero, vol. 47 (3), n. ${ }^{\circ} 259$, 2016, julio-septiembre, pp. 29-45 
Real Decreto 1612/2007, de 7 de diciembre, por el que se regula un procedimiento de voto accesible que facilita a las personas con discapacidad visual el ejercicio de derecho de sufragio (BOE n. ${ }^{\circ} 294$ de 08/12/2007).

Real Decreto 1494/2007, de 12 de noviembre, por el que se aprueba el Reglamento sobre las condiciones básicas para el acceso de las personas con discapacidad a las tecnologías, productos y servicios relacionados con la sociedad de la información y medios de comunicación social (BOE n. ${ }^{\circ} 279$, de 21/11/2007).

Ley 27/2007, de 23 de octubre, por la que se reconocen las lenguas de signos españolas y se regulan los medios de apoyo a la comunicación oral de las personas sordas, con discapacidad auditiva y sordociegas (BOE n. 255 de 24/10/2007).

Orden PRE /1822/2006, de 9 de junio, por la que se establecen criterios generales para la adaptación de tiempos adicionales en los procesos selectivos para el acceso al empleo público de personas con discapacidad (BOE n. ${ }^{\circ} 140$, de 13/06/2006).

Proposición no de Ley 161/000800, aprobada por la Comisión No Permanente para Políticas Integrales de la Discapacidad del Parlamento español, el 29 de noviembre de 2005 (BOCG, n. ${ }^{\circ} 43,29 / 11 / 2005$ ).

Declaración 1/2004 del Parlamento Europeo sobre los derechos de las personas sordociegas. 


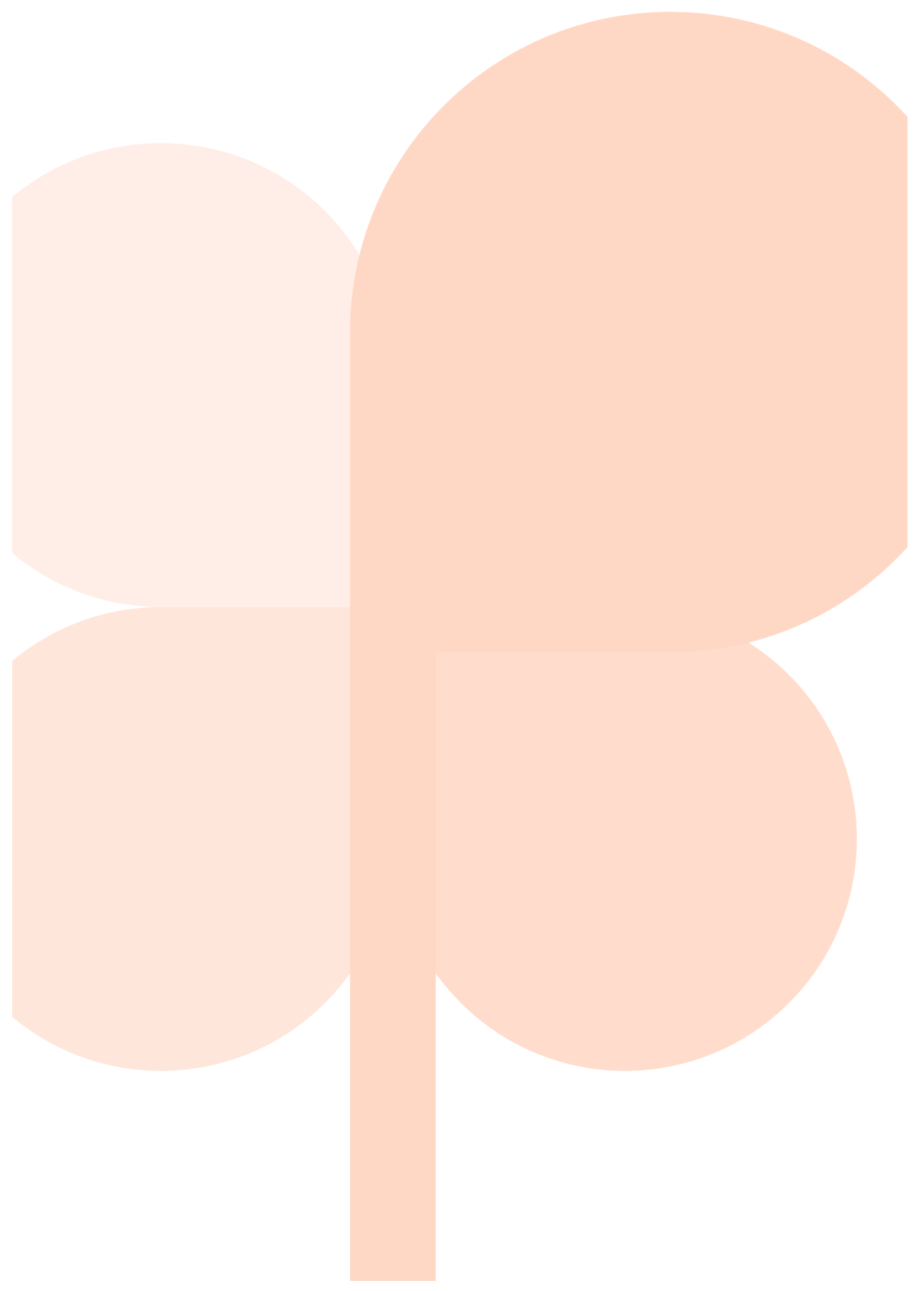

